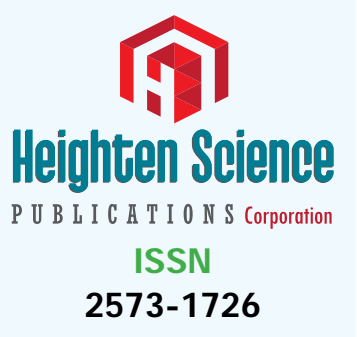

*Address for Correspondence: Dr. Steven Ross Murray, Department of Kinesiology, Colorado Mesa, University, 1100 North Avenue, Grand Junction, CO 81501, Tel: 970.248.1158; Email: smurray@coloradomesa.edu

Submitted: 15 November 2017

Approved: 22 November 2017

Published: 23 November 2017

Copyright: @ 2017 Pettitt RW, et al. This is an open access article distributed under the Creative Commons Attribution License, which permits unrestricted use, distribution, and reproduction in any medium, provided the original work is properly cited.

Keywords: Air displacement plethysmography; Anthropometrics; BIA; Body composition; Bodyfat
Research Article

\section{Influence of elbow angle on the reliability and validity of bioelectrical impedance analysis}

\author{
Robert W Pettittt,2, J acob B Mehrhoff ${ }^{3}$, David S Mandeville ${ }^{1,4}$, \\ Cherie D Pettitt ${ }^{2}$ and Steven Ross Murray ${ }^{5 *}$
}

${ }^{1}$ Office of University Research, Rocky Mountain University of Health Professions, Provo, UT, USA ${ }^{2}$ Department of Health Science, Rocky Mountain University of Health Professions, Provo, UT, USA

${ }^{3}$ Department of Health \& Human Performance, St. Thomas University, St. Paul, MN, USA

${ }^{4}$ Department of Anatomy \& Physiology, Rocky Mountain University of Health Professions, Provo, UT, USA

${ }^{5}$ Department of Kinesiology, Colorado Mesa University, Grand Junction, CO, USA

\section{Summary}

Hand-to-hand bioelectrical impedance (HH BIA) is a low-cost method to estimate percent body fat (\%BF). The BIA method is consistently reliable, but questions on validity remain. We have observed anecdotally that elbow position can render consistently different measures of \%BF while using $\mathrm{HH}$ BIA, thus leading to the question: Does elbow angle influence the validity of measures derived using HH BIA? The purpose of this study was to assess the effect of elbow position (i.e., IN=flexed to $90^{\circ}$ versus OUT=fully extended) on the reliability of HH BIA on 44 male and 24 female healthy adults (age $=21 \pm 2 \mathrm{yrs}, \mathrm{BMI}=23 \pm 3$ ). An additional aim was to assess the validity of the $\mathrm{HH}$ $\mathrm{BIA} \% \mathrm{BF}$ on a subset of subjects $(n=12)$ using air displacement plethysmography (BOD POD ${ }^{\circledR}$ ) as the criterion measure. The IN position was $\sim 4 \% B F$ lower than the OUT position for HH BIA ( $p=0.05$, effect size $=0.67$ ). Measures of \%BF for both trials for the IN [intraclass correlation coefficient (ICC) $=0.99$, coefficient of variation $(\mathrm{CV})=2.99 \%]$ and OUT $(\mathrm{ICC}=0.99, \mathrm{CV}=1.48 \%)$ conditions were highly reliable. On the subsample, the OUT $(18.3 \pm 6.7 \% \mathrm{BF})$ position exceeded both the IN $(14.5 \pm 7.4$ $\% \mathrm{BF}$ ) and the $\mathrm{BOD}^{\mathrm{POD}}{ }^{\circledR}(16.1 \pm 7.8 \% \mathrm{BF})$ measures $(\mathrm{p}<0.05)$; however, IN and BOD POD ${ }^{\circledR}$ measures of \%BF did not differ $(p=0.21)$. These findings support that $\mathrm{HH} B \mathrm{BI}$ is a reliable measure at both elbow positions; however, \%BF estimations vary considerably $(\sim 4 \%)$ with respect to the criterion measure depending on elbow position. The OUT position was found to overestimate criteria \%BF. Further research may reveal an optimum elbow angle position for $\mathrm{HH}$ BIA estimates of \%BF.

\section{Introduction}

Assessment of body composition and specifically changes in percentage body fat (\%BF) relative to fat-free mass are important for monitoring influences on athletic performance and risk associated with various chronic diseases [1]. Increasing adiposity is positively correlated with a rise in markers of systemic inflammation, including circulating tumor necrosis factor alpha and C-reactive protein, [2,3] and obesity has been identified as a comorbidity for a wide range of preventable cardiometabolic diseases [4]. Interventions aimed at targeting reductions in \%BF have evoked improvements in performance and health $[5,6]$. As such, identifying reliable and valid methods of measuring $\% \mathrm{BF}$ at lower costs is important.

Clinic- or laboratory-based measurements of \%BF include techniques such as dual x-ray absorptiometry analysis (DXA), hydrostatic densitometry, and air displacement plethysmography using the BOD POD ${ }^{\circledR}$ (Cosmed, International) $[7,8]$. Such technologies provide a "Gold Standard" or criterion measure of \%BF; however, each technique is 
both time intensive and cost prohibitive (i.e., an expense of $\$ 50,000$ USD or greater). For larger samples, rapid turnaround, and non-invasive assessments of $\% \mathrm{BF}$, many have turned to bioelectrical impedance analysis (BIA). For example, the National Health and Nutrition Examination Survey (NHANES) III utilizes BIA measurements to stratify population-based fat mass to fat-free mass ratios $[9,10]$.

Ideally, anthropometric field methods for assessing body composition would be low cost, portable, easy to perform for both the subject and tester, and would be repeatable and accurate. Although body mass index (BMI) has been used as a convenient anthropometric measure, the BMI lacks an ability to differentiate fat and fat-free mass [7]. Thus, BIA has become more popular for gathering body composition on a large sample size [9]. The BIA method is based on the principle that electric current flows preferentially through the path of least resistance in the body, i.e., water-containing compartment, with adipose tissue having low water content and hence higher impedance while conversely the fat-free mass has a high water content and lower impedance. Thus, impedance measures of resistance can be used to predict total body water and hence fat-free mass. Body-fat mass and $\% \mathrm{BF}$ are obtained by the difference with body weight. Various devices are available to measure body impedance, and many population-specific prediction equations have been published [11,12]. The BIA measures have been shown to have higher reliability compared to 6- and 7-site skin fold estimates of $\% \mathrm{BF}$ [13]. In addition, strong measurement agreement between BIA estimates and \%BF obtained using DXA measures have been observed for a general Caucasian sample [14].

The hand-to-hand bioelectrical impedance (HH BIA) is a non-invasive, low-cost, and mobile method used to estimate the clinical target variable of $\% \mathrm{BF}$ without the subject disrobing. Single frequency BIA has very high reliability [13]; however, research on the validity of BIA is equivocal with some reporting strong validity, $[13,15]$ and others raising questions about its validity $[6,16,17]$. We have observed anecdotally that \%BF estimates derived using hand-held BIA are influenced systematically by elbow position (i.e., flexed versus fully extended). Such a casual observation is plausible given that measurement of impedance $(Z)$ increases proportionately to conductor length $\left(\mathrm{L}^{2}\right)$ as illustrated using:

$$
Z=p L^{2} / V
$$

(Equation 1)

where $\mathrm{p}$ is the volume resistivity, and $\mathrm{V}$ is the tissue volume [18]. As the reliability of BIA is reportedly strong, a systematic adjustment in elbow position might yield stronger measurement agreement between BIA and that of a criterion \%BF measurement. Therefore, the aims of the present study were as follows: 1) to evaluate the effect of elbow position (i.e., a fully extended versus flexed $90^{\circ}$ ) on the reliability of $\% \mathrm{BF}$ measurements obtained from HH BIA, and 2) to determine if HH BIA measures from both positions were valid predictors of a criterion measurement of $\% \mathrm{BF}$.

\section{Methods}

Subjects

A total of 44 males and 24 females volunteered for our reliability study (age $=21 \pm 2$ yrs; $B M I=23 \pm 3$ ). The convenience sample consisted of healthy subjects residing as students at a university in the upper midwest region of the USA. The race of the sample was predominantly Caucasian. A subset of the sample $(n=12)$ also participated in the validation phase of the study.

\section{Procedures and equipment}

A handheld single wave, BIA device (OMRON ${ }^{\circledR}$ Model HBF-306) was evaluated with verified body mass and standing height using digital scale and stadiometer, respectively. These data along with the subject's self-identified activity level-normal 
or athletic-based on the description for calculating physical activity level provided by the manufacturer, and that same designator was used for each measure taken. In brief, the manufacturer provided a template for quantifying a cut-point for selecting the normal versus athletic designator using a metric for determining intensity, time, and frequency of exercise. Two trials were completed for each of the IN and OUT positions.

The validation phase of the study required obtaining a criterion measure of $\% \mathrm{BF}$ using air displacement plethysmography (BOD POD ${ }^{\circledR}$ ). The subjects were rested and wore a tight-fitting swimsuit and silicon head cap [19] for the test. Total lung capacity was evaluated with the device's spirometer, according to the manufacturer's user guidelines.

\section{Statistical Analyses}

Reliability of the two trials in each condition was assessed using intraclass correlation coefficients (ICC $\alpha$ ), typical error (TE), and the coefficient of variation (CV) [20]. Validity on the sub-group of measures for BIA in the IN and OUT positions relative to the criterion measure were evaluated using linear regression, whereby slope and y-intercept are reported along with standard error of estimate (SEE). To examine between-trial differences for the IN and OUT position, relative to the range of $\% \mathrm{BF}$ measurements within our sample, limits of agreement and a display of results using Bland-Altman plots [21] are provided. Differences between the IN and OUT positions (mean of two trials) were evaluated with a paired t-test, and comparison of the IN and OUT positions versus \%BF determined using the BOD POD ${ }^{\circledR}$ was evaluating using an analysis of variance with repeated measures. Bonferroni-adjusted pairwise analyses were used to evaluate significance. Level for rejecting the null hypotheses was set at $p<0.05$. The magnitude of the effect between test conditions were quantified using Cohen's d (i.e., mean difference divided by pooled SD). Summary statistics are expressed as mean \pm SD.

\section{Results}

Participants were consistently (Figure 1 ) about $\sim 4 \% \mathrm{BF}$ leaner (mean of two trials) for the IN $(13.4 \pm 6.1 \% \mathrm{BF})$ versus OUT $(17.5 \pm 6.2 \% \mathrm{BF})$ position assessed using handheld BIA ( $\mathrm{t}=29.9, \mathrm{p}<0.01, \mathrm{~d}=0.67)$. Reliability of two trials of the BIA measurements were strong for the IN (TE $=0.29 \% \mathrm{BF}, \mathrm{ICC}=0.99, \mathrm{CV}=2.99 \%$ error) and OUT (TE $=0.21$ $\% \mathrm{BF}, \mathrm{ICC}=0.99, \mathrm{CV}=1.48 \%$ error) positions. Mean differences between trials were near zero with the limits of agreement between trials being slightly larger for the IN versus the OUT position (Figure 2).

A subgroup of participants $(\mathrm{n}=12)$ completed the IN $(14.5 \pm 7.4 \% \mathrm{BF})$ and OUT $(18.3 \pm 6.7 \% \mathrm{BF})$ position in addition to an assessment using the BOD POD ${ }^{\circledR}(16.1 \pm 7.8$

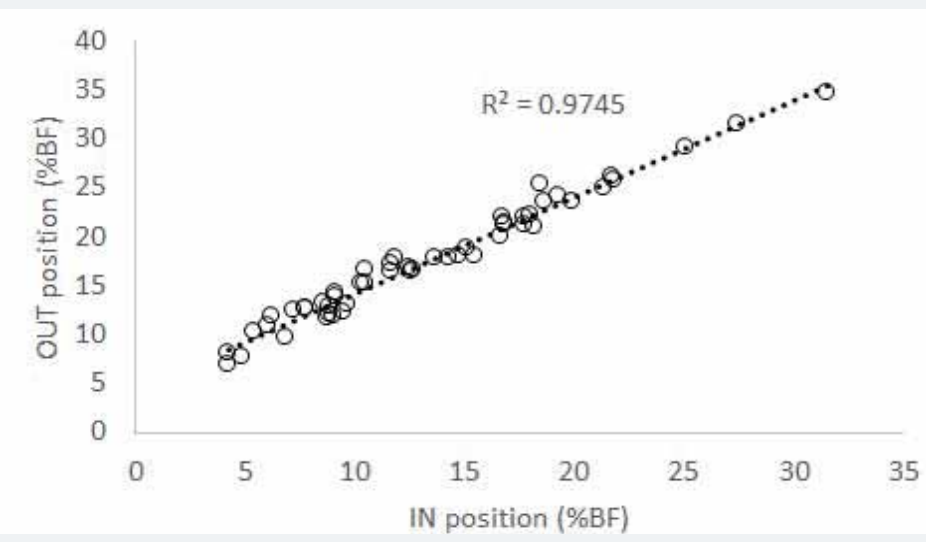

Figure 1: Consistency of rank-ordering between the IN and OUT positions for assessing \%BF using hand-held BIA. 
$\% \mathrm{BF}$ ). A significant main effect was observed between the measurement conditions $\left(\mathrm{F}=43.7, \mathrm{p}<0.01, \mathrm{n}_{\mathrm{p}}{ }^{2}=0.89\right.$ ). The OUT position was larger than either the IN position $(\mathrm{p}<0.01, \mathrm{~d}=0.54)$ and the BOD POD ${ }^{\circledR}(\mathrm{p}=0.04, \mathrm{~d}=0.30)$; however the IN position and the BOD POD $®$ measurement did not differ $(p=0.21, d=0.21)$. Measurements of each BIA condition were positively correlated with assessment of the BOD POD ${ }^{\circledR}$; however, the y-intercept for the OUT position was $4.43 \% \mathrm{BF}$ (Figure 3).

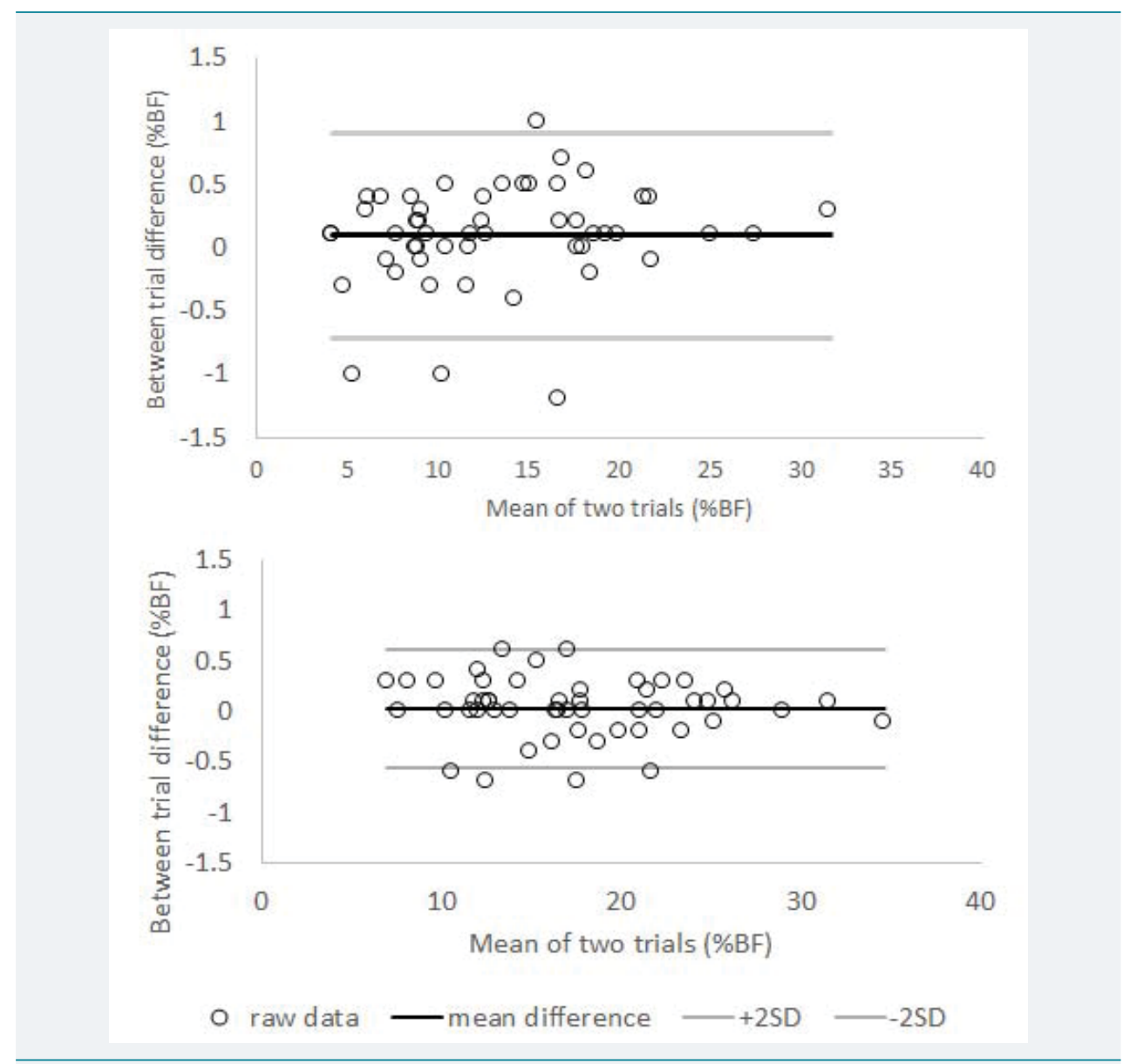

Figure 2: Bland-Altman plots for the between-trial measurements of \%BF for IN (top panel) and OUT (bottom panel) positions using hand-held BIA.

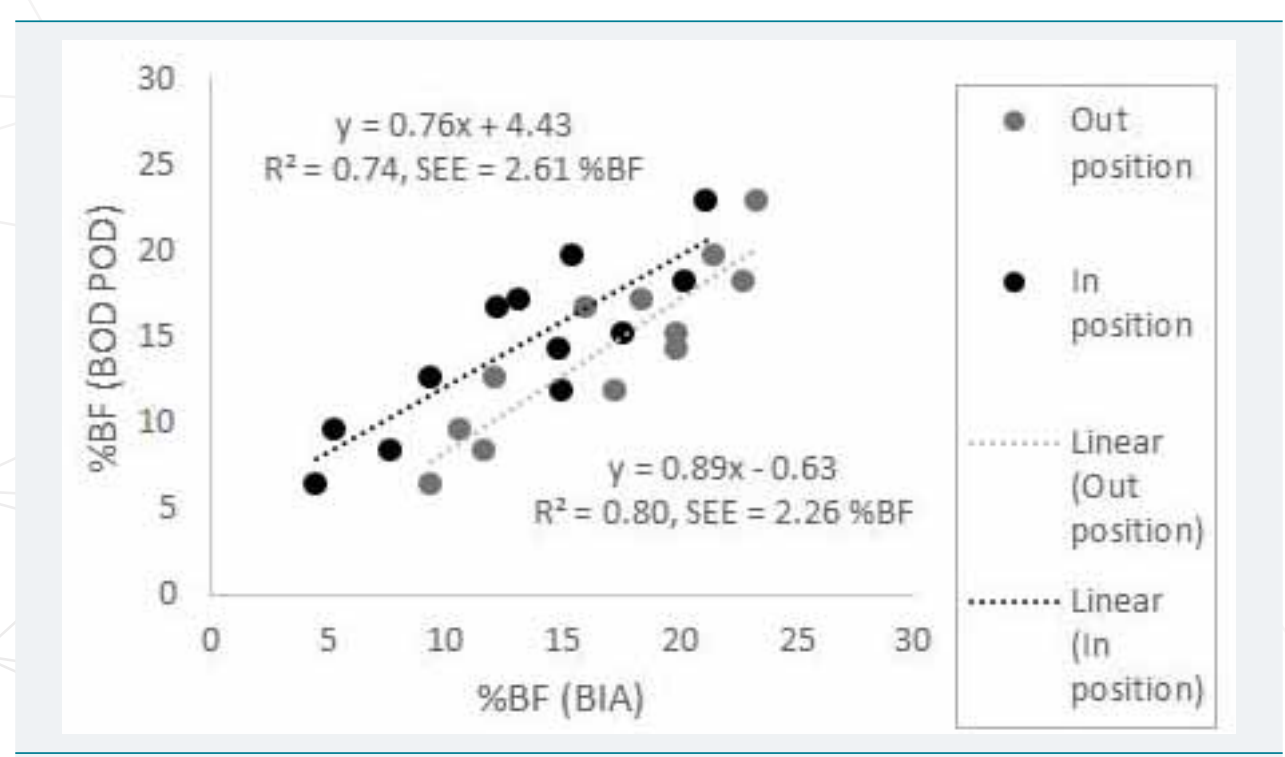

Figure 3: Linear regression of the IN (black font) and OUT (grey font) positions for hand-held BIA versus \%BF measured using the BOD POD® on a subgroup of participants $(n=12)$. 


\section{Discussion}

The IN versus OUT position for HH BIA supported the hypothesis that shortening the length of the tissue (equation 1) proportionally reduced impedance in a consistent manner (Figure 1) with a moderate effect size or magnitude of change (i.e., $d=0.67$ ). The consistency of variability between trials was not influenced by the absolute measurement of \%BF regardless of using the IN versus OUT position. Specifically, the variability was consistent between participants spanning lower to higher \%BF measurements (N.B., see x-axes in Figure 2). Finally, in contradiction to the manufacturer's user-directions, the OUT position overestimated true $\% \mathrm{BF}(\sim 2 \% \mathrm{BF})$; whereas, the IN position did not. The OUT versus IN position merely shifted the $\mathrm{y}$-intercept for predicting true \%BF (Figure 3). That said, a small effect size between the IN position and \%BF measured by the BOD POD ${ }^{\circledR}$ was observed and was nearly significant (i.e., $\mathrm{d}=0.22, \mathrm{p}=0.04$ ). Such an observation would suggest a more valid estimate of true \%BF may have been observed using the HH BIA device if we had opted for a $45^{\circ}$ as opposed to a $90^{\circ}$ elbow angle for the IN position.

The standard (OUT) position consistently overestimated true $\% \mathrm{BF}$ by $\sim 2 \% \mathrm{BF}$, an observation in contrast to other studies. For example, De Lorenzo et al. [16], reported BIA underestimated true \%BF by $2.6 \% \mathrm{BF}$; however, their criterion measure was DXA and not the BOD POD ${ }^{\circledR}$, and they evaluated whole-body BIA. Conversely, other studies using part or whole-body BIA have not observed significant differences with \%BF measures taken from the DXA $[9,13,22]$ or the BOD POD ${ }^{\circledR}[23]$. The type of BIA (i.e., lower body versus upper body) is an unlikely source of variance for comparing validity between studies because lower-body and upper-body BIA are highly correlated with each other [9] as well as with whole-body measures of impedance [22]. Thus, given the convenience and low cost of HH BIA, its strong correlation with lower - or whole-body BIA is attractive.

In the present study, reliability at the different elbow positions was established on the same day. Our reliability data from each elbow position are comparable to prior research $[9,23]$. Issues such as hydration and time of day can alter the reliability of BIA between days, $[5,24]$ and Lu et al. observed the CV for between-day reliability was $\sim 0.33 \%$ greater than the within-day CV for the same subjects. Thus, in interpreting our reliability findings, it would be reasonable to suggest that the HH BIA in either elbow position would detect a $0.5 \% \mathrm{BF}$ change as a result of a lifestyle intervention. At the cost of the device evaluated in the present study $(<\$ 100$ USD), the convenience of $\mathrm{HH}$ BIA for large lifestyle intervention studies is appealing.

To our knowledge, we are the first group to observe and report on consistently reliable differences on the measurement of \%BF using $\mathrm{HH}$ BIA at different elbow positions. Impedance was reduced relative to the conductor length and inversely to the cross-sectional area. In two separate studies [25,26], a reduction in cross-sectional area associated muscle tension produced a reduction in impedance. In the present study, we did not evaluate electroimpedancemyography, and therefore the precise underlying cause for our results is unknown.

Interestingly, $\% \mathrm{BF}$ as measured by the BOD POD ${ }^{\circledR}$ was $\sim$ midway between measurements obtained at either OUT or IN, albeit the sample size was not sufficient to detect the difference between the IN and BOD POD ${ }^{\circledR}$ measurements. Future investigators may wish to examine the $45^{\circ}$ elbow angle. Such a position might be ideal for yielding a more valid estimate of true \%BF using $\mathrm{HH}$ BIA.

In summary, there is continual need for establishing valid and reliable measurements of fat and fat-free mass that are affordable, portable, and sensitive for detecting changes from lifestyle interventions. The HH BIA technique appears to offer a reliable solution for such needs; however, those utilizing the BIA method must be mindful to use consistent 
testing positions, standardizing time of day for testing, along with the importance of educating subjects on how to maintain proper hydration [5,24]. Our results indicate elbow position can have a large influence on $\% B F$ prediction, and we recommend future research on the determination of the best elbow position for HH BIA testing.

\section{References}

1. Bosy-Westphal A, Muller MJ. Identification of skeletal muscle mass depletion across age and BMI groups in health and disease--there is need for a unified definition. Int J Obes (Lond). 2015; 39: 379386. Ref.: https://goo.gl/Kja6XR

2. Brooks GC, Blaha MJ, Blumenthal RS. Relation of C-reactive protein to abdominal adiposity. Am J Cardiol. 2010; 106: 56-61. Ref.: https://goo.gl/1BLif2

3. Pou KM, Massaro JM, Hoffmann U, Vasan RS, Maurovich-Horvat P, et al. Visceral and subcutaneous adipose tissue volumes are cross-sectionally related to markers of inflammation and oxidative stress: the Framingham Heart Study. Circulation. 2007; 116: 1234-1241. Ref.: https://goo.gl/Fw6eMg

4. Horton ES. Effects of lifestyle changes to reduce risks of diabetes and associated cardiovascular risks: results from large scale efficacy trials. Obesity (Silver Spring). 2009; 17: 43-48. Ref.: https://goo.gl/hfws6F

5. Ackland TR, Lohman TG, Sundgot-Borgen J, Maughan RJ, Meyer NL, et al. Current status of body composition assessment in sport: review and position statement on behalf of the ad hoc research working group on body composition health and performance, under the auspices of the I.O.C. Medical Commission. Sports Med. 2012; 42: 227-249. Ref.: https://goo.gl/99HjFg

6. Ballesteros-Pomar MD, Calleja-Fernandez A, Diez-Rodriguez R, Vidal-Casariego A, Blanco-Suarez $M D$, et al. Comparison of different body composition measurements in severely obese patients in the clinical setting. Nutr Hosp. 2012; 27: 1626-1630. Ref.: https://goo.gl/AaMuud

7. Brodie DA, Stewart AD. Body composition measurement: a hierarchy of methods. J Pediatr Endocrinol Metab. 1999; 12: 801-816. Ref.: https://goo.gl/s54AgH

8. Wagner DR, Heyward VH. Techniques of body composition assessment: a review of laboratory and field methods. Res Q Exerc Sport. 1999; 70: 135-149. Ref.: https://goo.gl/YACF4j

9. Lu HK, Chiang LM, Chen YY, Chuang CL, Chen KT, et al. Hand-to-Hand Model for Bioelectrical Impedance Analysis to Estimate Fat Free Mass in a Healthy Population. Nutrients. 2016; 8. Ref.: https://goo.gl/9kz7F5

10. Xiao J, Purcell SA, Prado CM, Gonzalez MC. Fat mass to fat-free mass ratio reference values from NHANES III using bioelectrical impedance analysis. Clinical nutrition (Edinburgh, Scotland). 2017. Ref.: https://goo.gl/GNDA9y

11. Kyle UG, Bosaeus I, De Lorenzo AD, Deurenberg P, Elia M, et al. Bioelectrical impedance analysis--part I: review of principles and methods. Clin Nutr. 2004; 23: 1226-1243. Ref.: https://goo.gl/HtoUme

12. Kyle UG, Bosaeus I, De Lorenzo AD, Deurenberg P, Elia M, et al. Bioelectrical impedance analysis-part II: utilization in clinical practice. Clin Nutr. 2004; 23: 1430-1453.Ref.: https://goo.gl/4rGzKU

13. Aandstad A, Holtberget $K$, Hageberg R, Holme I, Anderssen SA. Validity and reliability of bioelectrical impedance analysis and skinfold thickness in predicting body fat in military personnel. Military medicine. 2014; 179: 208-217. Ref.: https://goo.gl/5PpZpm

14. Stewart SP, Bramley PN, Heighton R, Green JH, Horsman A, et al. Estimation of body composition from bioelectrical impedance of body segments: comparison with dual-energy X-ray absorptiometry. Br J Nutr. 1993; 69: 645-655. Ref.: https://goo.gl/PBxETp

15. Hsueh-Kuan L, Chiang L, Chen Y, Chuang C, Chen K, et al. Hand-to-hand model bioelectric impedance analysis to estimate fat free mass in a health population. Nutrients. 2016; 8: 654. Ref.: https://goo.gl/oUMAUm

16. De Lorenzo A, Bertini I, lacopino L, Pagliato E, Testolin C, et al. Body composition measurement in highly trained male athletes. A comparison of three methods. J Sports Med Phys Fitness. 2000; 40: 178-183. Ref.: https://goo.gl/Ep66Yp

17. Lazzer S, Bedogni G, Agosti F, De Col A, Mornati D, et al. Comparison of dual-energy X-ray absorptiometry, air displacement plethysmography and bioelectrical impedance analysis for the assessment of body composition in severely obese Caucasian children and adolescents. Br J Nutr. 2008; 100: 918-924. Ref.: https://goo.gl/UTaCaM 
18. Turner AA, Bouffard M, Lukaski HC. Examination of bioelectical impedance errors using generalizability theory. Sports Med, Train Rehab. 1996; 7: 87-103. Ref.: https://goo.gl/tDzhsL

19. Peeters MW, Claessens AL. Effect of different swim caps on the assessment of body volume and percentage body fat by air displacement plethysmography. J Sports Sci. 2011; 29: 191-196. Ref.: https://goo.gl/shTJVt

20. Hopkins WG. Measures of reliability in sports medicine and science. Sports Med. 2000; 30: 1-15. Ref.: https://goo.gl/kqafAP

21. Bland JM, Altman DG. Statistical methods for assessing agreement between two methods of clinical measurement. Lancet. 1986; 1: 307-310. Ref.: https://goo.gl/8KF5kh

22. Lukaski HC, Siders WA. Validity and accuracy of regional bioelectrical impedance devices to determine whole-body fatness. Nutrition. 2003; 19: 851-857. Ref.: https://goo.gl/F22DPn

23. Vicente-Rodriguez G, Rey-Lopez JP, Mesana MI, Poortvliet E, Ortega FB, et al. Reliability and intermethod agreement for body fat assessment among two field and two laboratory methods in adolescents. Obesity (Silver Spring). 2012; 20: 221-228. Ref.: https://goo.gl/Pz47dw

24. Fogelholm M, van Marken Lichtenbelt W. Comparison of body composition methods: a literature analysis. Eur J Clin Nutr. 1997; 51: 495-503. Ref.: https://goo.gl/rAJ8aZ

25. McCullagh WA, Ward LC. Assessing limb movement using real-time bioimpedance recording (abstract). 2003 Australian Conference of Science and Medicine in Sport; Canberra: 2003 Australian Conference of Science and Medicine in Sport. 2003. Ref.: https://goo.gl/xBxFKF

26. McCullagh WA, Ward LC. Assessing limb movement by electroimpedancemyography. International Conference on Electrical Bioimpedance \& Electrical Impedance Tomography; Gdansk, Poland: ICEBI XII - EIT V. 2004; 291-294. Ref.: https://goo.gl/tqzo6v 